\title{
РАДИКАЛЬНЫЙ ИСЛАМИЗМ В ГЕРМАНИИ И ФРАНЦИИ: ТЕНДЕНЦИИ И ВЫЗОВЫ
}

\begin{abstract}
Аннотация. В настоящее время среди угроз для безопасности в Европе на первое место выходит радикальный исламизм. Количество джихадистов и радикально настроенных исламистов растет во всех европейских странах с каждым годом, война на Ближнем Востоке принесла Европе не только миллионы беженцев, но и радикализащию мусульманской общины, что привело к тому, что тысячи лии с паспортами европейских государств отправились воевать в ряды террористических группировок. Европейские правоохранители понимают растушую угрозу со стороны исламистских радикалов, но успехи по борьбе с данным явлением пока что достаточно скромные. Распространение идей радикального исламизма и рост его адептов требуют не только координации усилий спецслужб европейских государств, но и интенсивного диалога правительств, гражданского общества и мусульманской общественности Европьы.
\end{abstract}

Ключевые слова: исламизм, джихадизм, терроризм, безопасность, Германия, Франщия, $E C$.

В последние годы общей тенденцией для большинства европейских стран является резкий рост радикального исламизма. Террористические атаки, такие, как расстрел редакции юмористического журнала «Charlie Hebdo», нападение на концертный зал «Батаклан» в Париже, использование грузовиков для наезда на толпу в Ницце, Берлине, Стокгольме и других городах не имеют аналогов по численности жертв, резонансу и жестокости в сравнении с атаками левых или правых террористов.

Правоохранители стран ЕС признают, что в Сирии, в рядах таких террористических группировок, как «Исламское государство» ${ }^{1}$, «Аль-Нусра» ${ }^{2}$ и прочих, воюют сотни лиц с паспортами стран - членов ЕС, причём преимущественно это мигранты, приехавшие в Европу из стран Северной Африки, Ближнего Востока. Они являются питательной средой для вербовки эмиссарами террористических исламистских группировок. При этом они не только едут воевать за свою идеологию на Ближний Восток, но совершают теракты и в самой Европе. Так, за 2016 г. на территории ЕС было совершено 13 терактов и террористических атак, в ходе которых погибло 135 человек ${ }^{3}$. По подозрению в деятельности организаций исламистского и джихадистского толка за 2016 г. было арестовано 718 человек ${ }^{4}$.

(C) Камкин Александр Константинович - кандидат философских наук, ведущий научный сотрудник Центра германских исследований ИЕ РАН. Адрес: 125009, Россия, Москва, ул. Моховая, д. 11, стр. 3. E-mail: alexander.kamkin@yahoo.com.

DOI: http://dx.doi.org/10.15211/vestnikieran6201815

${ }_{1}^{1}$ Организация, запрещённая на территории Российской Федерации.

2 Организация, запрещённая на территории Российской Федерации.

${ }^{3}$ Источник: EU Terrorism Situation and Trend Report (TE-SAT), 2016; цит. по: Read more at the EU Terrorism Situation \& Trend Reports. The overall terrorist threat to the security of the EU remains acute // https://www.europol.europa. eu/crime-areas-and-trends/crime-areas/terrorism, June 2017. (электронный ресурс, дата обращения: 28.08.2018 г.)

4 Там же. 


\section{Идеологическая составляющая исламистского экстремизма}

Под исламизмом понимают форму политической идеологии с религиозным подтекстом. При этом исламисты стремятся сделать религию инструментом своей политики. Они выступают за реализацию всех положений ислама не только как свода нравственных установок и религиозных догматов, но и как универсального средства регулирования социальных, юридических, экономических и политических отношений. Подобная доктрина во многом прямо противоположна сложившимся за последние 200 лет либеральным устоям европейского общества и порой антагонистична им. При этом средством реализации своих целей избрали террор и геноцид, иными словами, установление своей догматики насильственным путём.

Следует отметить, что исламистских течений существует большое количество, не все исламисты считаются в ЕС и других странах экстремистами. Более того, некоторые политологи и исламоведы полагают, что даже салафиты - наиболее радикальные представители исламизма не являются поголовно экстремистами. Такой точки зрения придерживается в частности казахстанский политолог Талгат Мамырайымов, который считает, что экстремистским можно считать джихадистское крыло салафизма и хариджитов-такфиритов ${ }^{1}$.

Вообще салафизм - направление в исламе, идеологи которого призывают к возвращению ислама к исходным корням, состоянию первых веков существования этой религии. Следует отметить, что именно различные группировки радикалов-салафитов ведут войну против законного правительства Сирийской арабской республики и в других государствах Ближнего Востока и Африки. Идеологию салафизма исповедуют большинство экстремистских джихадистских группировок на Ближнем Востоке и их ячейки в Европе.

Большинство группировок радикальных исламистов стремятся создать глобальный халифат и позиционируют свою исламистскую идеологию в качестве альтернативы капитализму и светской демократии. Несмотря на то, что большинство исламистов выступают за восстановление халифата только в мусульманском мире, а не «ни в каком западных стран, включая США» ${ }^{2}$, они активно используют антизападную пропаганду для продвижения своих целей, включая вербовку неофитов в самих западных странах. При этом в своей пропаганде в европейских странах они активно используют тезис о якобы имеющем место унижении и угнетении мусульман в европейских странах, что позволяет консолидировать мусульман из различных стран.

При этом исламисты зачастую используют беженцев для вербовки неофитов. Так, в интервью газете «Rheinische Post» глава Ведомства Ханс-Георг Маасен заявил, что салафиты действуют в образе филантропов и сотрудников образовательных организаций. Они намеренно вступают в контакт с мигрантами и приглашают их в определённые мечети, чтобы завербовать для своих целей ${ }^{3}$. Следует отметить, что немецкие и другие европейские правоохранители не имеют такого широкого взгляда, как некоторые политологи и учёные из СНГ и заносят всех салафитов в разряд экстремистов, различая между «религиозно мотивированными» и джихадистами, склонными к насилию, которые выделаются в статистике в отдельную группу. При этом по всей Европе наблюдается резкое увеличение численности салафитов.

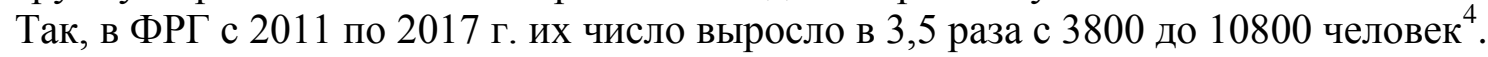

\footnotetext{
${ }^{1}$ Талгат Мамырайымов: не все салафиты - экстремисты и террористы // http://www.uralskweek.kz/2016/06/13/ talgat-mamyrajymov-ne-vse-salafity-ekstremisty-i-terroristy/

2 Hizb ut-Tahrir // https://www.counterextremism.com/sites/default/files/threat_pdf/Hizb\%20ut-Tahrir-01262018.pdf. (Электронный ресурс, дата обращения: 12.10.2018 г.).

3 Яковина И. Мигранты в Европе: главные риски // http://www.colta.ru/articles/society/8494 (Электронный ресурс, дата обращения: 12.10.2018 г.).

${ }^{4}$ Anzahl der Salafisten in Deutschland von 2011 bis 2017 // https://de.statista.com/statistik/daten/studie/445097/umfrage Научно-аналитический вестник ИЕ РАН, 2018, №6
} 
Если сформулировать вкратце основные идеологические маркеры исламизма, то прежде всего следует выделить совершенно отличное от европейского понимание прав человека (неравноправие женщин, смертная казнь в том числе за инакомыслие, как в случае с журналистом Хаштоги и известным шиитским проповедником Нимр ан-Нимром, казнённым в Саудовской Аравии в начале января 2016 г. ${ }^{1}$ ); отрицание демократии как фундаментального принципа европейской идентичности; исламисты отрицают светское законодательство европейских стран, требуя ввести наряду с ним, а то и вместо него нормы шариатского права и пр.

\section{Деятельность радикальных исламистов в Германии}

Германия в течение последних лет стала одной из мишеней радикальных исламистов. Так, один из самых резонансных терактов был совершён 19 декабря 2016 г., когда рождённый в Тунисе Анис Амри въехал на грузовике в толпу людей на рождественском рынке в Берлине, убив 12 и ранив ещё 48 человек. Спустя несколько дней он был застрелен полицией в Италии при оказании сопротивления. Немецкие правоохранители приводят данные, согласно которым, начиная с 11 сентября 2001 г., своеобразной точки отсчёта в плане выхода исламистского террора за пределы Ближнего Востока, в результате террористических атак исламистских погибло больше граждан ФРГ, чем от рук Фракции Красной Армии, которая действовала в Германии почти тридцать лет. Ещё в 2014 г. Федеральная уголовная полиция предупреждала, что наибольшая террористическая угроза в Германии исходит именно от радикальных исламистов. По данным Федерального Ведомства по охране Конституции ФРГ, по состоянию на апрель 2018 г. в Германии проживало 25810 исламистов и джихадистов ${ }^{2}$. Тенденция роста численности радикалов-исламистов растёт уже не первый год. Так, число лиц с салафитскими устремлениями возросло в 2017 г. на тысячу человек по сравнению с 2016 г. (с 9700 до 10800 человек) $)^{3}$. Также власти Германии определили приблизительно 760 лиц, которые, как считают правоохранители, намерены и способны совершить террористическую атаку. Более половины из них проживают в настоящее время Германии, а в настоящее время 153 находятся под стражей ${ }^{4}$.

Росту численности исламистов в Германии конечно в первую очередь содействовал миграционный кризис, когда Германия приняла с 2015 г. около 1,5 млн беженцев. При этом власти Германии предупреждают, что лица, ищущие убежище в стране, подвергаются риску радикализации под воздействием проживающих в ФРГ джихадистов, из которых в настоящее время в стране насчитывается около 10800 человек $^{5}$. По состоянию на апрель 2018 г. в совокупности около 1000 лиц, преимущественно выходцев из стран Ближнего Востока и Магриба, отправились сражаться в рядах террористических организаций в Сирии и Ираке. Из этого числа примерно одна треть с тех пор вернулась в Германию.

Однако создание спящих ячеек радикалов и различных организаций шло и ранее. Помимо салафитов из стран Ближнего Востока в Германии уже давно активно действуют различные группировки пантюркистов, турецких радикалов-гюленовцев и пр. Так, по состоянию

\footnotetext{
/anzahl-der-salafisten-in-deutschland/

${ }^{1}$ Казнь шиитского проповедника в Саудовской Аравии привела к массовым протестам // https://tass.ru/mezhduna rodnaya-panorama/2569672 (электронный ресурс, дата обращения: 15.10.2018 г.).

${ }^{2}$ Counter extremism project. Germany: Extremism \& Counter-Extremism. P. $4 / / \mathrm{https}: / /$ www.counterextremism. com/sites/default/files/country_pdf/DE-10092018.pdf (электронный ресурс, дата обращения: 15.10.2018 г.).

${ }^{3}$ Verfassungsschutzbericht 2017 - Fakten und Tendenzen - Kurzzusammenfassung. S. 25. // https://www.verfassungs schutz.de/de/oeffentlichkeitsarbeit/publikationen/verfassungsschutzberichte/vsbericht-2017-kurzzusammenfassung

(электронный ресурс, дата обращения: 17.09.2018 г.).

Там же.

${ }^{5}$ Там же.
} 
на 2017 г., в ФРГ насчитывалось около 10000 активистов пантюркистского «Милли Герюс»1.

\section{Деятельность радикальных исламистов во Франции}

Франция является одной из главных мишеней для радикальных исламистов. В отличие от Германии, радикальные исламисты устраивали теракты во Франции и ранее, что было обусловлено затяжной в Алжире. Теракты не закончились и после окончания войны. С 1994 по 1996 гг. Франция была жертвой серии нападений боевиков Алжирской вооружённой исламистской группы (GIA). В декабре 1994 г., боевики GIA угнали французский самолёт в Алжире, предположительно, с целью взорвать его над Парижем. В 1995 и 1996 гг. GIA устроила серию взрывов во Франции, в результате которых было в общей сложности убито 16 и ранено более 300 человек. Одна бомба была заложена рядом с еврейской школой, при взрыве было ранено 14 человек. В последние годы Франция испытала ряд смертоносных терактов, в том числе нападение в июле 2016 г. в Ницце, ноябрьские атаки активистов ИГИЛ в ноябре 2015 г. в Париже, а также нападение на редакцию сатирического журнала «Charlie Hebdo» и кошерные супермаркеты в январе 2015 г.

Так, 11 декабря 2018 г. радикал-исламист, родившийся во Франции, Шариф Шакт расстрелял из пистолета четырёх человек в Страсбурге. При этом преступник был хорошо известен полиции, так как уже неоднократно совершал преступления на территории Германии и Франции. Через два дня он был ликвидирован полицейским спецназом. 23 марта 2018 г. боевик-исламист захватил автомобиль в городе Каркассон, убив пассажира и ранив водителя. Затем боевик ранил ближайшего полицейского. Боевик, 26-летний Редуан Лакдим поехал в близлежащий город Требек в супермаркет. В результате четыре были убиты, включая офицера полиции, который обменял себя на заложника, трое других были ранены. Полиция позже обнаружила три самодельных взрывных устройства в супермаркете.

Первое крупное террористическое нападение на территории Франции за последние годы случилось 7 января 2015 г., когда действующие от имени йеменского филиала «Аль-Каиды» люди ворвались в офис французского сатирического журнала «Charlie Hebdo» с автоматами, убив 12 человек.

13 ноября 2015 г. восемь боевиков ISIS произвели целый ряд терактов в Париже и его окрестностях, убив 130 и ранив 350 человек. 14 июля 2016 г. проживающий в Ницце уроженец Туниса врезался на грузовике в толпу гуляющих на набережной, которые праздновали день взятия Бастилии, убив 86 человек и ранив более 430. 26 июля 2016 г. два боевика ИГИЛ ворвались в приходскую церковь в Сен-Этьене в Нормандии и убили священника.

В общей сложности, начиная с 2015 г., во Франции в ходе террористических актов было убито более 240 человек ${ }^{2}$.

Все эти теракты наглядно свидетельствуют об очень большой опасности, исходящей от радикальных исламистов. Правоохранители насчитали по состоянию на 2016 г. 15000 подозреваемых в терроризме. Франция является крупнейшим поставщиком боевиков из Европы для Ирака и Сирия, по состоянию на май 2016 г., более 2000 граждан Франции воевало на стороне террористических группировок ${ }^{3}$. Помимо этого, серьёзной проблемой для страны является проблема миграции и распространение радикального исламизма в тюрьмах, где процент мигрантов среди заключённых постоянно растёт. По различным оценкам, по состоянию на 2016 г. в исправительных учреждениях страны находилось свыше 1400 лиц, придержи-

\footnotetext{
${ }^{1}$ Там же.

${ }^{2}$ Counter extremism project. France: Extremism \& Counter-Extremism. P. 5 // https://www.counterextremism.com/ sites/default/files/country_pdf/FR-10112018.pdf (электронный ресурс, дата обращения: 12.10.2018 г.).

${ }^{3}$ Там же.
} 
вающихся радикального исламизма ${ }^{1}$.

Джихадисты добились успеха в вербовке французских граждан как в Интернете, так и в ходе личных контактов. В ноябре 2014г. ИГИЛ выпустил пропагандистское видео, призывающее французских мусульман совершать нападения во Франции, если они не могут попасть на подконтрольную ИГИЛ территорию. Данная террористическая группировка также запустила журнал на французском языке «Dar al Islam». Были нередки случаи, когда были завербованы с помощью пропагандистских видеороликов в Интернете несовершеннолетние подростки.

Таким образом, ситуацию с исламистским экстремизмом в обеих странах объединяют следующие моменты. Большое количество лиц с паспортами этих стран уехало участвовать в дхихаде и немалое их число вернулось обратно; есть приток неофитов из числа местного населения именно в мечети, где проповедуют радикалы; растёт число терактов на религиозной почве; происходит перенос внутренних межконфессиональных и межэтнических конфликтов на территорию этих государств (курдо-турецкий, арабо-израильский, суннито-шиитский и пр.). Разница заключается в более жёстких методах борьбы французских спецслужб (количество арестов в разы больше, чем в ФРГ). В то же время идёт активно сотрудничество спецслужб обеих стран, а также попытки диалога правительств, гражданского общества и представителей исламских религиозных объединений.

\section{Борьба правоохранительной системы с радикальным исламизмом}

Правоохранительные службы европейских стран и Европол ведут мониторинг и работы по противодействию распространению идеологии радикального исламизма, однако, пока что переломить ситуацию им не удаётся. Исследователи приводят следующие цифры по Европе в целом. Например, большинство арестованных за терроризм, подготовку терактов и экстремистскую деятельность, относились к группировкам джихадистов. Так, в 2014 г. было проведено 395 арестов, 687 в 2015 г. и 718 в 2016 г. ${ }^{2}$ Правда, следует отметить, что рост этих цифр прошёл только за счёт Франции. В других странах арестов проводилось на порядок меньше.

Руководящие лица стран ЕС отдают себе отчёт в росте данной угрозы. В частности, французский президент Эммануэль Макрон назвал контртерроризм своей главной внешнеполитической целью. В январе 2015 г. французское правительство начало кампанию StopDjihadisme, которая включает в себя онлайн-ресурсы, помогающие французским гражданам идентифицировать и сообщать о подозреваемых в терроризме, а также обучают французских граждан тому, что делать в случае нападения.

Помимо этого, стремясь противостоять угрозе радикальной радикализации, правительство начало эксперимент по изоляции подозреваемых в терроризме от остальной части заключённых. Правительство объявило об остановке данного эксперимента в конце октября 2016 г., после того, как возникли опасения, что программа будет только способствовать углублению радикализации среди заключённых.

В сентябре 2016 г. правительство Франции открыло первый из 12 запланированных центров дерадикализации в небольшом городке к западу от Парижа. Эта программа, в отличие от тюремного эксперимента, призвана реабилитировать людей, которые стали объектом вербовки радикалов. Однако данная программа также начала сразу же давать сбои. В январе 2017 г. один из участников программы был арестован после того как было обнаружено, что он после прохождения программы пытался отправиться в Сирию.

\footnotetext{
${ }^{1}$ Там же.

2 Trends in Extremist Violence and Terrorism in Europe through End-2016. P.7 // https://www.csis.org/analysis/trendsextremist-violence-and-terrorism-europe-through-end-2016 (электронный ресурс, дата обращения: 12.09.2018).
} Научно-аналитический вестник ИЕ РАН, 2018, №6 
Помимо программ адаптации и реабилитации исламистов и профилактических мер власти европейских стран активно прибегают к запретительным мерам. Так, в ФРГ была запрещена организация салафитов «Lies!», которая распространяла экстремистскую литературу в ФРГ.

Таким, все усилия правоохранителей пока что не способствуют исправлению ситуации. Наиболее продуктивным способом борьбы с радикальным исламизмом должно стать налаживание взаимодействия между органами государства, общественными организациями и религиозными центрами мусульман, духовными лидерами диаспор. Не секрет, что среди правоохранителей европейских стран не так много экспертов, способных дать адекватный анализ духовной исламской литературы с целью определения - относится ли она к умеренному или радикальному исламу.

Государственные структуры, гражданские активисты в Европе прилагают большие усилия для адаптации приезжающих из стран исламского мира к европейским нормам жизни, и наоборот, в обществе проводятся просветительские акции по приобщению европейцев к традиционной исламской культуре. Так, в конце 2018 г. в Саксонии (ФРГ) была запущена программа просветительских исламских недель в школах, имамы рассказывали ученикам об исламе и его традициях, устраивались экскурсии в мечети. На более широком уровне Центральный совет мусульман в ФРГ ведёт активную работу по формулировке положений «демократического ислама», или ислама, подходящего немецким нормам жизни ${ }^{1}$. Одновре́менно периодически проводится «Исламская конференция», где представители духовенства и государства обмениваются мнениями по актуальным вопросам. Европейские политики выступают за вовлечение мусульман в государственное управление. Основной мыслью европейского политического истеблишмента является то, что без тесного взаимодействия с духовными лидерами мусульманской диаспоры в Европе не получится полноценного диалога. В противном случае маховик взаимного отчуждения и европейцев и мусульман будет только раскручиваться, что приведёт к радикализации как принимающего общества, так и «новых европейцев».

\section{Список литературы}

Камкин А.К. Межнациональные конфликты в Европе // Европа XXI века. Новые вызовы и риски. Под общ. ред. Громыко Ал.А., Федорова В.П., Нестор-История, М., СПб, 2017. С. 269286.

Политический экстремизм в современной ФРГ // Современная Германия. Экономика и политика. Под общ. ред. В.Б. Белова. ИЕ РАН, Весь мир. М., 2015. С. 505-533.

Яковина И. Мигранты в Европе: главные риски. URL: http://www.colta.ru/articles/society/ 8494.

Талгат Мамырайымов: не все салафиты - экстремисты и террористы. URL: http://www. uralskweek.kz/2016/06/13/talgat-mamyrajymov-ne-vse-salafity-ekstremisty-i-terroristy/

\section{References}

Kamkin A.K. Mezhnatsionalnye konflikty v Evrope // Evropa XXI veka. Novye vysovy i riski. Pod obschey redaktsiyey Gromyko Al.A., Fyodorova V.P., Nestor-Istoriya, M., SPb, 2017.S. 269286.

Kamkin A.K. Politischeskiy ekstremism v sovremennoy FRG // Sovremennaya Germaniya.

\footnotetext{
1 Deutsche Muslime sollen einen «deutschen Islam» definieren // https://www.welt.de/politik/deutschland/article
} 179266416/Neue-Islamkonferenz-Deutsche-Muslime-sollen-einen-deutschen-Islam-definieren.html. Научно-аналитический вестник ИЕ РАН, 2018, №6 
Ekonomika i politika. Pod obschey redaktsiyey Belova V.B. IE RAN, Ves mir. Moskva, 2015. S. 505-533.

Anzahl der Salafisten in Deutschland von 2011 bis 2017 // https://de.statista.com/statistik/ daten/studie/445097/umfrage/anzahl-der-salafisten-in-deutschland/

Deutsche Muslime sollen einen «deutschen Islam» definieren // https://www.welt.de/politik/ deutschland/article179266416/Neue-Islamkonferenz-Deutsche-Muslime-sollen-einen-deutschenIslam-definieren.html.

Talgat Mamyraymynov: ne vse salafity - extremisty I terroristy. URL: http://www.uralskweek. kz/2016/06/13/talgat-mamyrajymov-ne-vse-salafity-ekstremisty-i-terroristy/

The overall terrorist threat to the security of the EU remains acute. URL: https://www.europol.europa.eu/crime-areas-and-trends/crime-areas/terrorism.

Counter extremism project. Hizb-ut-Tahrir. URL: https://www.counterextremism.com/ sites/default/files/threat_pdf/Hizb\%20ut-Tahrir-01262018.pdf.

Yakovina I. Migranty v Evrope: glavnye riski. URL: http://www.colta.ru/articles/society/8494. https://tass.ru/mezhdunarodnaya-panorama/2569672.

Counter extremism project. Germany: Extremism \& Counter-Extremism. URL: https://www.counterextremism.com/sites/default/files/country_pdf/DE-10092018.pdf.

Verfassungsschutzbericht 2017 - Fakten und Tendenzen - Kurzzusammenfassung. URL: https://www.verfassungsschutz.de/de/oeffentlichkeitsarbeit/publikationen/verfassungsschutzbericht e/vsbericht-2017-kurzzusammenfassung.

Counter extremism project. France: Extremism \& Counter-Extremism https://www.counterex tremism.com/sites/default/files/country_pdf/FR-10112018.pdf.

Trends in Extremist Violence and Terrorism in Europe through End-2016. URL: https://www.csis.org/analysis/trends-extremist-violence-and-terrorism-europe-through-end-2016.

\section{Radical Islamism in Germany and France - trends and challenges}

Author. Alexander Kamkin, Candidate of Sciences (Philosophy), Leading researcher of Center of German studies, Institute of Europe, Russian Academy of Sciences. Address: 11-3, Mokhovaya str., Moscow, Russia, 125009. E-mail: alexander.kamkin@yahoo.com.

Abstract. Currently radical Islamism becomes thread number one among challenges to European security. The number of jihadists and radical islamists grows in all European countries from year to year. War in the Middle East caused not only of refugees in Europe, but also radicalization of Moslem community, which resulted in thousands persons with European countries citizenship coming as fighters of various terrorist groups. European law enforcement bodies realize the growing thread of islamist radicals, but efforts in combating this are still modest. Spread of radical Islamism ideas and growth of its adepts require not only coordination of special forces of European countries, but also an intensive dialogue of governments, civil society and Moslem community of Europe.

Key words: Islamism, jihadism, terrorism, security, France, Germany, EU.

DOI: http://dx.doi.org/10.15211/vestnikieran6201815 